\title{
Analysis of Essential Elements for Plants Growth Using Instrumental Neutron Activation Analysis
}

\author{
R. L. Njinga, ${ }^{1}$ M. N. Moyo, ${ }^{2}$ and S. Y. Abdulmaliq ${ }^{3}$ \\ ${ }^{1}$ Department of Physics, Ibrahim Badamasi Babangida University, Lapai, Niger State, Nigeria \\ ${ }^{2}$ Head of Unit for Dosimetry, National Radiation and Protection Agency, Bastos, Yaounde, Cameroon \\ ${ }^{3}$ Department of Crop Production, Ibrahim Badamasi Babangida University, Lapai, Niger State, Nigeria
}

Correspondence should be addressed to R. L. Njinga; njingaraymond@yahoo.co.uk

Received 28 July 2013; Revised 15 August 2013; Accepted 17 August 2013

Academic Editor: Othmane Merah

Copyright (C) 2013 R. L. Njinga et al. This is an open access article distributed under the Creative Commons Attribution License, which permits unrestricted use, distribution, and reproduction in any medium, provided the original work is properly cited.

\begin{abstract}
In this study, a total of ten essential elements for plants growth in the Guinea savanna region of Niger State in Northern Nigeria have been identified in the soils using instrumental neutron activation analysis. The experimental results show good agreement with certified or literature values within the agreed percentage range of $\pm 2.35 \%$ to $\pm 8.69 \%$. However, the concentration distributions of the ten identified elements in the soil samples within the studied area for plants growth revealed the following: Fe (123.4 ppm), Mn (2100.7 ppm), K (5544.3 ppm), Al (54752.4 ppm), Ti (3082.9 ppm), Ca (4635 ppm), V (54.3 ppm), Na (857.5 ppm), Mg (13924.1 ppm), and Dy $(12.1 \mathrm{ppm})$. A further analysis of the two fundamental soil physical parameters for healthy growth of some common crops like egusimelon, groundnut, rice, yams, soybeans, cassava, and potato analyzed in this work revealed a $\mathrm{pH}$ range of $4.0 \mathrm{pH}-8.0 \mathrm{pH}$ and a temperature range of $28.0^{\circ} \mathrm{C}$ to $29.3^{\circ} \mathrm{C}$, which are optimal for plant nutrients availability in the soils within the study area.
\end{abstract}

\section{Introduction}

Plants require at least sixteen elements for normal growth and completion of their life cycle. They need relatively large amount of nitrogen, phosphorus, and potassium referred to as primary nutrients usually supplied in fertilizers [1]. The three secondary elements $\mathrm{Ca}, \mathrm{Mg}$, and $\mathrm{S}$ are virtually required in smaller amounts. $\mathrm{Ca}$ and $\mathrm{Mg}$ are usually supplied with liming materials while $S$ with fertilizer materials [2]. Contaminants in rainfall also supply $4.5 \mathrm{~kg}$ to $9.1 \mathrm{~kg}$ of nitrogen and sulphur per acre each year depending on the local air quality [3].

The micronutrients consist of seven essential elements which are boron, copper, chlorine, iron, manganese, molybdenum, and zinc. These elements occur in very small amounts in both soil and plants, but their role is as important as the primary nutrients $[4,5]$. A deficiency of one or more of the micronutrients can lead to severe depression in growth, yield, and crop quality. Some soils do not contain sufficient amounts of these nutrients to meet the plant's requirement for rapid growth and good production. In this case, supplemental micronutrients for rapid growth and good yield have to be applied in the form of foliar sprays with adequate knowledge of the elemental concentrations. Thus, this work seeks to analysze the essential elements for plants growth using instrumental neutron activation analysis in seven local government areas (LGAs) of Niger state, namely, Paikoro, Lapai, Mokwa, Katcha, Bida, Agaie, and Suleja local government areas of Niger State.

Plants absorb the essential elements through their root systems or their leaves in various forms [1]. In general, soil contains large amounts of all the elements, but only a very small percentage of these total amounts are actually useful for plant growth [6]. This is viewed in the case of iron content exceeding 50,000 ppm and the portion available to plants is less than $5 \mathrm{ppm}$ [7]. The availability of nutrients to plants in the form shown in Table 1 greatly relates to the chemical properties of the element, the soil $\mathrm{pH}$, interactions with soil colloids, and soil physical conditions such as temperature and moisture [8].

The soil solution holds most nutrients in the ionic forms indicated in Table 1 in proportion to the amounts held on the soil [9]. Plants absorb both cations and anions from the soil 
TABLE 1: Primary forms of some nutrients intake by plants.

\begin{tabular}{lcc}
\hline Elements & Symbols & Forms used by plants \\
\hline Nitrogen & $\mathrm{N}$ & $\mathrm{NH}_{4}^{+}$and $\mathrm{NO}_{3}{ }^{-}$ \\
Phosphorus & $\mathrm{P}$ & $\mathrm{HPO}_{4}{ }^{2-}$ and $\mathrm{H}_{2} \mathrm{PO}_{4}^{-}$ \\
Potassium & $\mathrm{K}$ & $\mathrm{K}^{+}$ \\
Calcium & $\mathrm{Ca}$ & $\mathrm{Ca}^{2+}$ \\
Magnesium & $\mathrm{Mg}$ & $\mathrm{Mg}^{2+}$ \\
Iron & $\mathrm{Fe}$ & $\mathrm{Fe}^{2+}$ and Fe \\
Manganese & $\mathrm{Mn}$ & $\mathrm{Mn}^{2+}$ \\
Zinc & $\mathrm{Zn}$ & $\mathrm{Zn}^{2+}$ \\
Copper & $\mathrm{Cu}$ & $\mathrm{Cu}^{2+}$ \\
Molybdenum & $\mathrm{Mo}$ & $\mathrm{MoO}_{4}{ }^{2-}$ \\
Nickel & $\mathrm{Ni}$ & $\mathrm{Ni}^{2+}$ \\
Sodium & $\mathrm{Na}$ & $\mathrm{Na}^{+}$ \\
\hline
\end{tabular}

solution in an equilibrium rate often referred to as buffering process. A detail about this process is discussed in [1].

However, the soil supplies thirteen of the fifteen elements required for nutrition of higher plants, which must be available continuously and in balanced proportions to support photosynthesis and other metabolic processes of plants. The Guinea Savannah zones of Niger State, as indicated in Figure 1, are of iron-rich ferralitic and ferruginous soil types $[10,11]$.

The major soil types that favour agroecological development include Alfisols, Inceptisols, Entisols, and Vertisols. Alfisols is the most common in the Guinea Savannah region. As derived from pre-Cambrian crystalline basement complex, leached and slightly acid soils with $\mathrm{pH}$ between 5.0 and 7.0 are commonly found in the Guinea Savannah zones [11]. Over the years, the Nigeria Savannah soils have been investigated severally by $[2,10,11]$ in the areas of morphology and the survival of cereals and other crops under drought conditions. However, the characteristics and management of the problems associated with the soils of the Nigerian Savannah focusing on the morphological properties, particle size, and chemical properties have been studied and published [12]. Some works have been carried out in the areas of major and minor trace element analyses in aquatic and terrestrial environments such as sediments, rocks, and soils [13-15]. Also, [16] investigated sulphur in Northern Nigeria soils, while [17] equally studying the Alfisols of the Savannah only on one element (Iron). However, the assessment of soil fertility restoration under fallow in Nigerian Savannah included soil property, organic matter, and few inorganic elements has been performed by [2]. The Guinea Savannah soil types are susceptible to erosion because of their sandy nature [11]. It is for this reason that soil amendment processes, mostly fertilizer applications and manuring, have been constantly applied to the Guinea Savannah zones. However, such agrarian interventions may not be self-assigned if the soil micro- and macronutrients in the form of trace elements are not known.

1.1. Theory of Neutron Activation Analysis. Neutron activation analysis referred to as an analytical method was introduced by


FIGURE 1: Sampling zoned according to the vegetation types in Nigeria.

Harvesy and Levi in 1936 [18]. De Soete et al. [19] followed the development of the method from its inception and gave an indepth account of the various aspects. Between 1980s and 90s, several publications on the refined theory and techniques of neutron activation analysis (NAA) have been released [2026]. The sensitivity of the method has been described in several places with the recent review being that of [24] and can be considered to be about ppb level for reactor irradiations. The sensitivity is a function of nuclear parameters of the element in question: neutron cross section, isotope abundance, halflife, gamma-ray abundance, available neutron flux, length of irradiation, detector efficiency, matrix composition, and the total sample size.

In the determination of activated trace elements, the selectivity of the NAA method shows striking properties of certainty and versatility [27]. Apart from measurements of the half-life and the type of energy of the produced isotopes precisely, the ratio of the activity of the isotope of interest to the interfering activities can be enhanced by changing irradiations and decay time before counting. Changing the neutron spectrum has also been shown [19] to minimize interferences due to fast neutron-induced reactions by choosing an irradiation site in the reactor with a pure thermal flux. NAA has a lead over other methods because of the possibility of simultaneous assaying of a majority of elements in representative mass of substance with considerable sensitivity as compared to other conventional techniques which require special sample preparation procedures before analysis [28].

In reactor instrumental neutron activation analysis, decomposition and radiochemical separation of the radioactive sample are shown [19] not to be necessary. All problems related to the decomposition of the sample and separation (dissolution, contamination, and losses) are avoided. The radionuclides are determined nondestructively on the basis 
of the differences in their decay rates via measurements at different decay intervals using high-resolution detectors. It does not require complicated handling as well. This aspect is very important when analyzing essential elements for plants growth or in the case of materials that are difficult to dissolve, for example, silicon-based samples or ceramics. Better detection limits of desired elements can be achieved by optimizing irradiation parameters (energy, rate of the neutrons, irradiation time, and decay and counting times). The influence of the matrix is usually negligible since most matrices appear to be transparent. Most samples are composed of $\mathrm{H}$, $\mathrm{C}, \mathrm{O}, \mathrm{N}, \mathrm{P}$, and $\mathrm{Si}$ and hardly form any radioactive isotopes. This makes the method highly sensitive for measuring trace elements with low detection limits.

In the relative standardization method of NAA employed in this work, the concentration of an element in the unknown sample was calculated by irradiating the unknown sample and a standard containing a known amount of the element of interest together in the reactor. If the unknown sample and the standard are both measured on the same detector and the decay and irradiation times between the two are corrected, the mass of the element in the unknown will be calculated by using the half-life of the measured isotope. The equation com-monly used to calculate the mass of an element in the unknown sample relative to the standard is

$$
\frac{A_{\mathrm{sam}}}{A_{\mathrm{std}}}=\frac{m_{\mathrm{sam}}}{m_{\mathrm{std}}} \frac{\left(e^{-\lambda T_{d}}\right)_{\mathrm{sam}}}{\left(e^{-\lambda T_{d}}\right)_{\mathrm{std}}},
$$

where $A$ is induced activity of the sample (sam) and standard (std), $m$ is mass of the element, $\lambda$ is decay constant for the isotope, and $T_{d}$ is decay time.

For a stable reactor flux and when performing short irradiations, the irradiation, decay, and counting times are normally fixed for all samples and standards such that the timedependent factors canceled out. Thus, (1) is simplified

$$
C_{\text {sam }}=C_{\text {std }} \frac{W_{\text {sam }}}{W_{\text {std }}} \frac{A_{\text {sam }}}{A_{\text {std }}},
$$

where $C$ is concentration of the element and $W$ is weight of the sample and standard.

The neutron activation technique, through its nuclear character, allows the analysis of a wide variety of elements in widely differing matrices, making it a powerful analytical tool, not only in trace analysis but also in determining alloy elements and minor constituents [29]. As a powerful analytical technique, it has applications in a broad range of disciplines such as plant nutrients, archeology, environmental monitoring, geology, human sample analysis, and materials science [30].

A major advantage in the INAA of nutrients for plants growth matrices is that the matrix elements $\mathrm{C}, \mathrm{H}, \mathrm{N}$, and $\mathrm{O}$ produce negligible $\gamma$-ray activity to interfere with the determination of trace elements. The ${ }^{13} \mathrm{C}(n, \gamma){ }^{14} \mathrm{C}$ and ${ }^{2} \mathrm{H}(n, \gamma)$ ${ }^{3} \mathrm{H}$ reactions produce very small activities of the non- $\gamma$ emitters ${ }^{3} \mathrm{H}$ and ${ }^{14} \mathrm{C}$, and the ${ }^{18} \mathrm{O}(n, \gamma){ }^{19} \mathrm{O}$ and ${ }^{15} \mathrm{~N}(n, \gamma){ }^{16} \mathrm{~N}$ reactions give very short-lived ${ }^{19} \mathrm{O}(27 \mathrm{sec})$ and ${ }^{16} \mathrm{~N}(7.1 \mathrm{sec})$. All of these reactions have extremely low thermal neutron cross sections. However, the high concentration of $\mathrm{P}$ in many biological tissues (e.g., bone) reduces the detestability of some $\gamma$ emitters because ${ }^{32} \mathrm{P}$ from the ${ }^{31} \mathrm{P}(n, \gamma){ }^{32} \mathrm{P}$ reaction, although not a $\gamma$-emitter, gives a bremsstrahlung continuum in the $0-1.7 \mathrm{MeV}$ region of the $\gamma$-ray spectrum. Similarly, traces of $\mathrm{Na}, \mathrm{K}$, and $\mathrm{Cl}$ in plant samples may produce high activities of ${ }^{24} \mathrm{Na}(15 \mathrm{~h}),{ }^{42} \mathrm{~K}(12 \mathrm{~h})$, and ${ }^{38} \mathrm{Cl}$ (37 $\left.\mathrm{min}\right)$ [31].

The basic principle of INAA is neutron-induced reactions which is preceded by the interaction of neutron with a target nucleus via a nonelastic collision and forming a compound nucleus in an excited state. The excitation energy of the compound nucleus is due to the binding energy of the neutron with the nucleus. The compound nucleus will almost instantaneously deexcite into a more stable configuration through emission of one or more characteristic prompt gamma rays. In many cases, this new configuration yields a radioactive nucleus which also deexcites (or decays) by emission of one or more characteristic delayed gamma-rays, but at a much slower rate according to the unique half-life of the radioactive nucleus. Depending upon the particular radioactive species, half-lives can range from fractions of a second to several years. With respect to the time of measurement, NAA falls into two categories: prompt gamma-ray neutron activation analysis (PGNAA), where measurements take place during irradiation, and delayed gamma-ray neutron activation analysis (DGNAA), where the measurements follow radioactive decay. The latter operational mode is more common; thus, when one mentions NAA, it is generally assumed that measurement of the delayed gamma rays is intended. About $70 \%$ of the elements have properties suitable for measurement by NAA.

The basic equation that will be employed for the calculation of the essential elements for plant growth after irradiation of the soil samples with the miniature research reactor with the account of decayed $\gamma$-rays in NAA is

$$
{ }^{A} X+{ }_{0}^{1} n \longrightarrow{ }^{A+1} X+\gamma .
$$

NAA utilizes the fact that the number of atoms of the radioisotopes produced ${ }^{A+1} X$ depends on the cross section of the neutron-nuclide reaction, duration of irradiation, and the half-life of the radioisotope produced. The activity evaluation after irradiation of the soil samples is based on the equation given as

$$
A=N \sigma \varphi\left(1-e^{-\lambda t_{i}}\right)
$$

where $N$ is number of target atoms, $\sigma$ is cross section, $\varphi$ is flux parameter, $t_{i}$ is irradiation time, and $\lambda$ is decay constant.

The term $\left(1-e^{-\lambda t_{i}}\right)$ in (4) is called the saturation faction. It approaches unity when the rate of formation of the radioisotopes is equal to the rate of its decay. The measured count rate $R$ of the $\gamma$-rays from the decay of a specific isotope ${ }^{A+1} X$ in the irradiated soil samples is related to the amounts of the original stable isotope ${ }^{A} X$ in the sample through

$$
A=\varepsilon I_{\gamma} N \sigma \varphi\left(1-e^{-\lambda t_{i}}\right) e^{-\lambda t_{d}},
$$

where $\varepsilon$ is efficiency of the detector used and $I_{\gamma}$ is absolute gamma ray abundance. 


\section{Soil Sampling}

The surfaces were scraped to remove smeared soil. This was necessary to minimize the effects of contaminant migration interferences due to smearing of material from other levels. Hand augers with 4-inch stainless steel auger buckets with cutting heads of diameter of $10 \mathrm{~cm}$, advanced by simultaneously pushing and turning using an attached handle with extensions, were used to advance boreholes and collection of the soil samples in the shallow subsurface intervals of $30 \mathrm{~cm}$. Soil samples of about $1 \mathrm{~kg}$ were collected and stored in a polythene container as shown in Table 2. The samples were air-dried, and roots and any other extraneous materials were manually removed. The samples were sealed in plastic bags for transport to the laboratory at the Centre for Energy Research and Training, Ahmadu Bello University, Zaria.

The recordings of basic physical characteristics at each site were based on standard procedures. About $20 \mathrm{~g}$ of the soil samples from each of the samples obtained were weighed using Mettler weighing balance, and $40 \mathrm{~mL}$ of distilled water were added at each point to form a solution. The solutions were stirred for 30 minutes to homogenize the mixture. At this stage, the soil pHs were measured using MERCK $\mathrm{pH}$ universal indicator. The thermometer was also immersed in each of the solutions in the seven LGAs for temperature readings.

In CERT, these samples were dry-sieved through a $2 \mathrm{~mm}$ nylon mesh and a portion wet-sieved through a $150 \mu \mathrm{m}$ mesh. The fractions were air-dried in Kraft paper bags at ambient temperature and, later on, oven-dried at approximately $80^{\circ} \mathrm{C}$ for 2 days, ground, homogenized, and stored in nitric acid acidified distilled water-washed polyethylene containers.

Digestion of soil samples was carried out using Nitric acid (69\% purity), perchloric acid (65\% purity), and hydrochloric acid (28\% purity). Soil sample measuring $0.5000 \pm 0.0002 \mathrm{~g}$ was digested in a mixture of $10 \mathrm{~mL}$ concentrated Nitric acid, $3 \mathrm{~mL}$ perchloric acid, and $2 \mathrm{~mL}$ hydrochloric acid for 30 minutes using microwave-accelerated reaction system.

The digested soil samples were analyzed alongside standard reference material (SRM) of the National Institute of Standard and Technology (NIST, 2709 San Joaquin Soil specifically coal fly ash 1633b and the IAEA-soil-7 for Quality Assurance and Control).

\section{Experimental Procedure}

Each of the soil samples was crushed to fine powder by means of pulverized and immediately packaged into plastic containers. These samples were tightly sealed by smearing the inner rims of each container lid with Vaseline wax and the lid assembled gap with candle wax before applying masking adhesive tape. These samples were then stored for a duration of 35 days for attainment of secular equilibrium. The irradiation procedures were performed based on both short half-life radionuclides and long half-life radionuclides.

3.1. Irradiation Protocols. For the short half-lives radionuclides, all the samples with equal amount and matrix texture of coal fly ash $1633 \mathrm{~b}$ (NIST) standards reference materials (SRM) and IAEA Soil-7 with the weights of $150 \mathrm{mg}-250 \mathrm{mg}$
TABLE 2: Sampling sites with horizontal depth.

\begin{tabular}{lcc}
\hline $\begin{array}{l}\text { Local government area } \\
\text { in Niger State }\end{array}$ & $\begin{array}{c}\text { Laboratory } \\
\text { identification }\end{array}$ & Vertical depth \\
\hline Paikoro 1 & PAI-C1 & $30 \mathrm{~cm}$ \\
Paikoro 2 & PAI-C2 & $30 \mathrm{~cm}$ \\
Lapai 1 & LAP-E1 & $30 \mathrm{~cm}$ \\
Lapai 2 & LAP-E2 & $30 \mathrm{~cm}$ \\
Mokwa 1 & MOK-J1 & $30 \mathrm{~cm}$ \\
Mokwa 2 & MOK-J2 & $30 \mathrm{~cm}$ \\
Katcha 1 & KAT-K1 & $30 \mathrm{~cm}$ \\
Katcha 2 & KAT-K2 & $30 \mathrm{~cm}$ \\
Bida 1 & BID-L1 & $30 \mathrm{~cm}$ \\
Bida 2 & BID-L2 & $30 \mathrm{~cm}$ \\
Agaie 1 & AGA-AE1 & $30 \mathrm{~cm}$ \\
Agaie 2 & AGA-AE2 & $30 \mathrm{~cm}$ \\
Suleja 1 & SUL-IE1 & $30 \mathrm{~cm}$ \\
Suleja 2 & SUL-IE2 & $30 \mathrm{~cm}$ \\
\hline
\end{tabular}

The numbers 1 and 2 indicate two random locations within a local government area.

were irradiated for two minutes in the outer channel (B4) which is away from the reactor core, at a neutron flux setting of $2.5 \times 10^{11} \mathrm{n} / \mathrm{cm}^{2} / \mathrm{sec}$. For long half-lives radionuclides, the samples with the weights of $150 \mathrm{mg}-250 \mathrm{mg}$, together with some SRM, were irradiated for six hours in the inner channel (B2), which is close to the core of the nuclear research reactor at a neutron flux setting of $5.0 \times 10^{11} \mathrm{n} / \mathrm{cm}^{2} / \mathrm{sec}$.

After irradiation, the samples and standard, were ejected from the reactor via the pneumatic transfer process and allowed to decay to an appropriate dead time. In the case of the short irradiated samples, the short half-lives elements of interest $\mathrm{Al}, \mathrm{Ca}, \mathrm{Mg}$, Ti, V, Mn, $\mathrm{Dy}, \mathrm{Na}, \mathrm{K}$, and $\mathrm{Cl}$ were obtained based on two protocols.

(i) First short-count was performed immediately after irradiation, and each of the samples and standards were counted for five minutes using high purity germanium (HPGe) detector.

(ii) The second short-count was done after a decay period of two hours after irradiation, and the counting of gamma-rays in form of energies was performed using HPGe detector for 2 to 3 hrs for SRM and all the other samples.

In the case of the long irradiated samples, two protocols were established in order to obtain any of the following elements: As, Br, La, Sm, Yb, U, Sc, Cr, Fe, Co, Zn, Se, Rb, Cs, Ba, Eu, Lu, $\mathrm{Hf}, \mathrm{Ta}, \mathrm{Sb}$, and $\mathrm{Tb}$.

(i) The first stages of counting were done after 4 to 5 days of decay, and both types of samples (SRM and all the other samples) counted for 10 minutes.

(ii) The second stage of the counting was performed after nine days for each type, that is, SRM, and all the other samples counted for sixty minutes. 
TABLE 3: Physical soil parameters in the sampling sites.

\begin{tabular}{|c|c|c|c|c|}
\hline Local government area in Niger State & Laboratory identification & $\mathrm{pH}$ values & Nature of soil & Temperature ${ }^{\circ} \mathrm{C}$ \\
\hline Paikoro 1 & PAI-C1 & 6.8 & Slightly acidic soil & 29.00 \\
\hline Paikoro 2 & PAI-C2 & 7.1 & Slightly alkaline soil & 28.90 \\
\hline Lapai 1 & LAP-E1 & 6.6 & Slightly acidic soil & 28.80 \\
\hline Lapai 2 & LAP-E2 & 6.2 & Slightly acidic soil & 28.87 \\
\hline Mokwa 1 & MOK-J1 & 6.2 & Slightly acidic soil & 28.68 \\
\hline Mokwa 2 & MOK-J2 & 6.2 & Slightly acidic soil & 28.50 \\
\hline Katcha 1 & KAT-K1 & 6.7 & Slightly acidic soil & 28.67 \\
\hline Katcha 2 & KAT-K2 & 6.8 & Slightly acidic soil & 28.30 \\
\hline Bida 1 & BID-L1 & 6.7 & Slightly acidic soil & 28.70 \\
\hline Bida 2 & BID-L2 & 6.5 & Slightly acidic soil & 28.22 \\
\hline Agaie 1 & AGA-AE1 & 7.3 & Slightly alkaline soil & 28.35 \\
\hline Agaie 2 & AGA-AE2 & 6.4 & Slightly acidic soil & 28.18 \\
\hline Suleja 1 & SUL-IE1 & 6.2 & Slightly acidic soil & 29.80 \\
\hline Suleja 2 & SUL-IE2 & 6.5 & Slightly acidic soil & 29.10 \\
\hline
\end{tabular}

TABLE 4: Quality control data for coal fly ash 1633b (NIST) and IAEA-soil-7 reference material.

\begin{tabular}{|c|c|c|c|c|c|c|}
\hline \multirow{2}{*}{ Elements } & \multicolumn{2}{|c|}{ Coal fly ash 1633b } & \multirow{2}{*}{ PDC values } & \multicolumn{2}{|c|}{ IAEA-soil-7 } & \multirow{2}{*}{ PDC values } \\
\hline & This work & Certified values & & This work & Certified values & \\
\hline Dy (\%) & 18.10 & 17.00 & -6.47 & - & - & - \\
\hline $\mathrm{Na}(\%)$ & 0.21 & 0.20 & -5.00 & 0.26 & 0.24 & -8.33 \\
\hline $\operatorname{Mg}(\%)$ & 0.89 & 0.49 & -80.89 & 0.68 & 1.13 & 39.82 \\
\hline $\mathrm{Al}(\%)$ & 14.6 & 15.05 & 2.99 & 4.94 & 4.70 & -5.11 \\
\hline $\mathrm{Ca}(\%)$ & 1.41 & 1.51 & 6.62 & 0.31 & 0.30 & -3.33 \\
\hline $\mathrm{Ti}(\%)$ & 0.74 & 0.79 & 6.33 & 16.11 & 16.30 & 1.16 \\
\hline K (\%) & 1.80 & 1.95 & 7.69 & 1.23 & 1.21 & -1.65 \\
\hline $\mathrm{V}(\mathrm{ppm})$ & 280.00 & 295.60 & 5.28 & 69.40 & 66.00 & -5.15 \\
\hline $\mathrm{Mn}(\mathrm{ppm})$ & 128.70 & 131.80 & 2.35 & 647.00 & 631.00 & -2.54 \\
\hline
\end{tabular}

All the above-mentioned counting procedures were carried out based on Table 3 in a separate set-up with the gamma-ray HPGe detector and Pd-shield to ensure safety of the analyst and the associated electronic components. The gamma-rays from the samples were measured using the HPGe detector. The multipurpose gamma ray analysis software WINSPAN 2004 [32] version was used for the peak identification, spectra analysis, and quantification of the elements present.

The detector was calibrated in energy certified radioactive sources: ${ }^{137} \mathrm{Cs}$ emitting gamma-ray energy of $662 \mathrm{KeV}$ and ${ }^{60} \mathrm{Co}$ emitting two gamma-rays at 1172 and $1332.5 \mathrm{keV}$. Efficiency curve for the gamma-ray high purity germanium (HPGe) detector (ORTEC), model number "GEM-30195," has been developed and published [33].

\section{Results and Discussion}

From the temperature distributions and $\mathrm{pH}$ values in Table 3, it is show that the plant nutrients within these sites are optimum for proper growth. This is so because the $\mathrm{pH}$ value range for proper plants growth is 5.5 and 7.0. However, PAI-C2 (Paikoro2) and AGA-AE1 (Agaie1) were exceptional with $\mathrm{pH}$ values of 7.1 and 7.3, respectively showing alkaline soils properties.
Quality control data is the process of controlling the usage of data with known quality measurement for an application or a process. This is achieved when data quality assurance process which is the evaluation of data inconsistency or corrections has been performed. Based on the results shown in Table 4, the percentage deviation from the certified (PDC) reference materials coal fly ash $1633 \mathrm{~b}$ and IAEA-soil-7 showed an agreed percentage range of $\pm 2.35 \%$ to $\pm 8.69 \%$ except in the case of $\mathrm{Mg}$ with a deviation of $-80 \%$ for coal fly ash $1633 \mathrm{~b}$ and $39.82 \%$ for IAEA-soil-7. This result is very obvious because of the two nuclear reactions; ${ }^{27} \mathrm{Al}(n, p){ }^{27} \mathrm{Mg}$ and ${ }^{26} \mathrm{Mg}(n, \gamma)$ ${ }^{27} \mathrm{Mg}$. This error was corrected by measuring the reaction contribution from the $(n, p)$ due to ${ }^{27} \mathrm{Al}$ and subtracting the same from $(n, \gamma)$ reaction due to ${ }^{26} \mathrm{Mg}$.

From the quality assurance data analysis procedures, the elemental concentrations of the soil samples obtained randomly within two strategic farming locations in Paikoro, Lapai, Mokwa, Katcha, Bida, Agaie, and Suleja local government areas in Niger State, Nigeria, are shown in Table 5.

In order to adequately analyze these elemental concentrations of the seven LGAs, the average values of each of the nine elements in Table 5 were transformed into Table 6 , where the average values of each of the ten elements from the two sampling locations in each LGA are evaluated. 
TABLE 5: Elemental concentration in the soil samples for plants growth.

\begin{tabular}{|c|c|c|c|c|c|c|c|c|c|c|}
\hline Sam & $\mathrm{Mn}$ & $\mathrm{K}$ & $\mathrm{Fe}$ & $\mathrm{Al}$ & $\mathrm{Ti}$ & $\mathrm{Ca}$ & $\mathrm{V}$ & $\mathrm{Na}$ & $\mathrm{Mg}$ & Dy \\
\hline 1 & $24 \pm 0.2$ & $70 \pm 0.6$ & $8 \pm$ & 0.7 & $30 \pm 0.8$ & 50 & .7 & .2 & 0.5 & $27 \pm 0.5$ \\
\hline & .3 & & & & $0 \pm 0.2$ & & & & & \\
\hline & $06 \pm 0.1$ & $7780 \pm 0.4$ & $218.23 \pm 0.2$ & $134114 \pm 0.5$ & $3360 \pm 0.5$ & $5180 \pm 0.2$ & $4.9 \pm 0.5$ & $347.1 \pm 0.5$ & & \\
\hline & & $8260 \pm 0.9$ & & & $0 \pm 0.2$ & & & & & \\
\hline Iol & $279 \pm 0.2$ & $10020 \pm 0.5$ & 0 & $0 \pm 0.4$ & $3660 \pm 0.6$ & 7020 & $91.99 \pm 0.9$ & & & \\
\hline & & & & & & & & & & \\
\hline 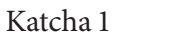 & 0 & $5130 \pm$ & & & 37 & & & & & \\
\hline & & & & & & & & & & \\
\hline B & .4 & $3580 \pm 0.5$ & & 29 & 175 & & & & & \\
\hline $\mathrm{Bic}$ & $40 \pm 0.3$ & 208 & & & $2400 \pm$ & & & & & \\
\hline & & & & & & & & & & \\
\hline & & & & & & & & & & \\
\hline & & $6960 \pm 0$ & & & $3850 \pm$ & & & & & 0.6 \\
\hline uleja 2 & $513 \pm 0.5$ & $2590 \pm 0.7$ & $141 \pm 0.1$ & $68900 \pm 0.8$ & $3130 \pm 0.6$ & $4400 \pm 0.6$ & $95.9 \pm 0.3$ & $1040 \pm 0.9$ & $2920 \pm 0.1$ & $6.21 \pm 0.2$ \\
\hline
\end{tabular}

TABLE 6: Average elemental concentration per LGA.

\begin{tabular}{|c|c|c|c|c|c|c|c|c|c|c|}
\hline Sampling sites & $\mathrm{Mn}$ & $\mathrm{K}$ & $\mathrm{Fe}$ & $\mathrm{Al}$ & $\mathrm{Ti}$ & $\mathrm{Ca}$ & $\mathrm{V}$ & $\mathrm{Na}$ & $\mathrm{Mg}$ & Dy \\
\hline Paikoro (Av) & 1722.5 & 3695 & 19.61 & 8560 & 2215 & 3135 & 18.95 & 210.2 & 2038 & 4.13 \\
\hline Lapai (Av) & 1022.4 & 8020 & 162.67 & 131057 & 3175 & 5175 & 79 & 282.45 & 12505.5 & 13.72 \\
\hline Mokwa (Av) & 298.9 & 8145 & 210.42 & 62950 & 3415 & 9810 & 96.345 & 480.25 & 2015 & 16.5 \\
\hline Katcha (Av) & 3845 & 4355 & 361.97 & 47950 & 2830 & 1720 & 51 & 394.5 & 20050 & 1.41 \\
\hline Bida (Av) & 6755 & 2830 & 83.11 & 30700 & 2075 & 2775 & 25.3 & 374 & 9430 & 34.39 \\
\hline Agaie (Av) & 648.5 & 6990 & 10.51 & 32000 & 4380 & 5490 & 20.55 & 800 & 48185 & 8.28 \\
\hline Suleja (Av) & 413 & 4775 & 15.51 & 70050 & 3490 & 4340 & 89 & 3350.5 & 3245 & 6.005 \\
\hline Mean value & 2100.8 & 5544.3 & 123.4 & 54752.4 & 3082.9 & 4635 & 54.3 & 857.5 & 13924.1 & 12.1 \\
\hline
\end{tabular}

Av stands for average values.

Concentrations are measured in ppm.

Iron in soil exists in the ferrous $\left(\mathrm{Fe}^{++}\right)$and ferric $\left(\mathrm{Fe}^{+++}\right)$ forms [34]. The Guinea Savannah zones of Niger State are of iron-rich ferralitic and ferruginous soil types. Ferric iron compounds have low solubility in the soil solution, and conditions that favour formation of these compounds decrease iron availability. The soil $\mathrm{pH}$ values for the seven LGAs ranged from 6.2 to 7.3, which invariably reduces the iron concentrations. This was the case observed in Suleja with the minimum average value of Fe concentration of $15.51 \mathrm{ppm}$, in Agaie with minimum value of $10.51 \mathrm{ppm}$ and in Paikora with minimum value of $19.61 \mathrm{ppm}$. The $\mathrm{pH}$ values of the two random locations of these three LGAs were 6.2 and 6.5 for Suleja 1 and 2, 6.4 and 7.3 for Agaie 1 and 2, and 6.8 and 7.1 for Paikoro 1 and 2. Based on the iron plant-analysis interpretations for some common Guinea Savannah crops in Table 7, the average results shown in Table 6 indicate that the Fe content in Paikoro is $19.61 \mathrm{ppm}$. This interpretation in terms of soybeans and cassava is deficient and sufficient for potato as depicted in Table 7. For Kacha with average value of 361.97 ppm, Fe content is high for all the crops listed in Table 7. For the remaining LGAs Lapai, Mokwa, and Bida, the Fe concentrations are sufficient for the crops listed in Table 7. However, the distribution from the Febar in Figure 2 shows that the percentage distributions of $\mathrm{Fe}$ in Mokwa and Lapai were approximately $20 \%$ while in Kacha is $40 \%$. In Paikoro and Suleja, the distribution is $2 \%$ and Agaie is $1.5 \%$.
The probable variation of Fe in the soil samples analyzed may be due to the types of crops cultivated and farming system practiced in the regions where the samples were collected. Niger State is a Savannah region where crops are grown with their root within 10 to $30 \mathrm{~cm}$ in depth for the plant nutrients [35]. Another reason may be due to the land fallow system [2] that is practiced within the seven local government areas allowing the soil to replenish its nutrients after some fallow time. The result of this analysis shows that the concentrations of these ten elements are within the expected range for soils [1]. The ten elements in Tables 5 and 6 were categorized according to major, minor, and trace levels. The major elements include magnesium, aluminum, calcium, titanium, and potassium, while sodium and manganese are in minor level and dysprosium in trace level.

The average concentration of aluminum in Table 6 ranges from 8560 ppm in Paikoro (2\%) to 131057 ppm in Lapai (32\%) and was generally high across the soil samples that were analyzed in the seven local government areas in Niger State. Factors such as bush burning and excessive clearing of field may have contributed to the overall concentration of $\mathrm{Al}$ in the soil matrix. Although the physiological function of $\mathrm{Al}$ in plants is not clear, it is evident that high levels of $\mathrm{Al}$ can have a negative effect on plant growth, especially in non-Al-tolerant plant species like wheat. 
TABLE 7: Iron plant-analysis interpretations for common Guinea Savannah crops [34].

\begin{tabular}{lcccc}
\hline Crop & Deficient & Low & Sufficient & High \\
\hline Soybeans & $<30 \mathrm{ppm}$ & $30-50 \mathrm{ppm}$ & $51-350 \mathrm{ppm}$ & $>350 \mathrm{ppm}$ \\
Maize & $<10 \mathrm{ppm}$ & $10-50 \mathrm{ppm}$ & $51-250 \mathrm{ppm}$ & $>250 \mathrm{ppm}$ \\
Potato & - & $<11 \mathrm{ppm}$ & $11-300 \mathrm{ppm}$ & $>300 \mathrm{ppm}$ \\
Groundnut & $<10 \mathrm{ppm}$ & $10-50 \mathrm{ppm}$ & $51-250 \mathrm{ppm}$ & $>250 \mathrm{ppm}$ \\
Cassava & $<20 \mathrm{ppm}$ & $20-30 \mathrm{ppm}$ & $31-250 \mathrm{ppm}$ & $>250 \mathrm{ppm}$ \\
\hline
\end{tabular}



FIGURE 2: Elemental concentration of soil samples obtained in seven local government areas in niger state.

Manganese is a micronutrient whose concentration in plants enhances the growth of soybean, groundnut, cassava, potato, egusimelon, rice, and maize [34]. The concentration range of manganese within the 7 local government areas was $2015.0 \mathrm{ppm}$ in Mokwa with a minimum percentage value of $1.8 \%$. The maximum concentration of $50 \%$, equivalent to concentration value of $12505.5 \mathrm{ppm}$, was observed in Lapai. The mean value of $13866.1 \mathrm{ppm}$ was observed across the seven LGAs. The average concentration range of sodium (Table 6) was observed in Paikoro LGA with a minimum percentage value of $2.2 \%$ equivalent to the concentration value of 210.2 ppm as shown in Figure 1. The maximum percentage value of $58 \%$ and concentration of 3350.5 ppm were observed in Suleja LGA. Meanwhile, the mean value of $\mathrm{Na}$ of $857.5 \mathrm{ppm}$ was observed across the ten LGAs. $\mathrm{Na}$, as a nutrient, normally supports crops cultivation like spinach obtained through its root of about 5 to $10 \mathrm{~cm}$ in depth and cash crops cultivated with their roots relatively deep inside the soil $(\sim 60 \mathrm{~cm}$ downward) like cocoa, kolanuts, bitter kola, and so forth obtained within the sampling LGAs. From the bar chart (Figure 1), the percentage distributions of the average concentration of each of the ten elements analyzed in the seven LGAs are shown on each of the bars. From the Mn-bar, the percentage (\%) distribution in each LGA shows that Mn was approximately $48 \%$ in Bida, followed by $25 \%$ in Katcha and $7 \%$ in Lapai. In Agaie and Mokwa, it was $4 \%$ and 2\%, respectively. Magnesium intake by some oil seed like crops such as groundnut, soya bean, egusimelon, beniseed is very essential. These crops are seriously cultivated in Niger State and this work revealed that within the seven LGAs of studies, the mean value of magnesium was $13924.1 \mathrm{ppm}$, which is relatively high. As shown in Tables 5 and 6, magnesium is observed to be evenly distributed. The average concentration of calcium in the seven LGAs ranges from $1720.0 \mathrm{ppm}$ in Katcha to $9810.0 \mathrm{ppm}$ in Mokwa. The calcium concentration range required by plants [31] is between 0.1 and $0.2 \%(\%=1000 \mathrm{ppm})$. However, calcium shows relatively even distributions within the seven LGAs because the enrichment factor such as dead animals' bones that have decayed or burnt during bush burning exercise may invariably lead to increase in the calcium content of the soils.

Low concentration of vanadium is beneficial to microorganisms, animals, and higher plants [1]. Increases in plant growth have been observed in rice and corn attributed to vanadium [7]. A normal concentration of vanadium required for plant growth is 2.0 parts per billion (ppb), whereas normal vanadium concentration in plant material averages about $1.0 \mathrm{ppm}$ [36]. The concentration of vanadium within the seven LGAs was averagely low (54.3 ppm), and the range of $11.6 \mathrm{ppm}$ observed in Agaie LGA and a high average value of $96.3 \mathrm{ppm}$ were observe in Mokwa. Also, potassium is required by plant usually in the ranges of 1.0 to $4.0 \%$ [5] for proper plants functions, including carbohydrate metabolism, enzyme activation, osmotic regulation, and efficient use of water [36]. The average concentration of potassium ranges from 3695.0 ppm in Paikoro to 8145.0 ppm in Mokwa LGAs.

The average concentration of titanium obtained within the seven LGAs ranges from $2075.0 \mathrm{ppm}$ in Bida to 4380.0 ppm in Agaie. However, no clear evidence of a biochemical role of titanium has been reported. Reference [37] described its possible catalytic function in nitrogen fixation by symbiotic microorganisms and in photooxidation of nitrogen compounds by higher plants and some processes of photosynthesis. Titanium is not an essential element for plant nutrition. It was observed by [38] that there is an increase of chlorophyll in tomato plants grown in culture solution after spraying with Ti-chelate solution, which is evidence for the biochemical role of titanium in plants. The average concentration of dysprosium obtained in the seven LGAS ranges from $1.405 \mathrm{ppm}$ in Katcha to $1650.0 \mathrm{ppm}$ in Mokwa. It has been observed that the average range of concentration of dysprosium in soil should be from $3.8 \mathrm{ppm}$ to $5 \mathrm{ppm}[9,39]$.

Dysprosium can therefore be described to be present in trace level. Dysprosium is a member of the group of elements 
referred to as rare elements. Thus, this mineral may not be required for plant nutrition though it may be of other uses to plant [40]. Bida, Mokwa, and Lapai LGAs registered an average value of dysprosium to be $34.39 \mathrm{ppm}, 16.5 \mathrm{ppm}$, and $13.72 \mathrm{ppm}$, respectively. However, low concentration of dysprosium was observed in Katcha, Paikoro Agaie, and Suleja LGAs, with values of $1.41 \mathrm{ppm}, 4.13 \mathrm{ppm}, 8.28 \mathrm{ppm}$, and $6.01 \mathrm{ppm}$, respectively.

\section{Conclusion}

A total of ten elements have been identified in the soils samples as essential elements for plants growth in the seven LGAs (Paikoro, Lapai, Mokwa, Katcha, Bida, Agaie, and Suleja) in the Guinea Savanna region of Niger state in Northern Nigeria using instrumentation neutron activation analysis. The accuracy of measurements evaluated, by analyzing coal fly ash 1633b SRM and IAEA Soil-7 compared well with the certified values of the trace elements of interest identified. The experimented results show good agreement with certified or literature values within the agreed percentage range of $\pm 2.35 \%$ to $\pm 8.69 \%$. The study of the soil samples from farming locations in the seven LGAs has been analyzed for essential elements suitable for plants growth. The average values of Fe (123.4 ppm), Mn (2100.7 ppm), K (5544.3 ppm), Al (54752.4 ppm), Ti (3082.9 ppm), Ca (4635 ppm), V (54.3 ppm), Na (857.5 ppm), Mg (13924.1 ppm), and Dy $(12.1 \mathrm{ppm})$ were obtained within the farming sites. However, the most common range of soil $\mathrm{pH}$ is $4.0-8.0 \mathrm{pH}$, and the range for optimal availability of plant nutrients for most crops is 6.5 to $7.0 \mathrm{pH}$, while the temperature is $28.0^{\circ} \mathrm{C}$ to $29.3^{\circ} \mathrm{C}$ as obtained in this work. These results indicate healthy growth of the common crops such as egusimelon, groundnut, rice, yams, soybeans, cassava, and potato, vegetables grown within these LGAs.

\section{Acknowledgment}

The authors acknowledged the Centre for Energy Research and Training, CERT, Ahmadu Bello University, Zaria, Nigeria, for providing the nuclear reactor and its ancillary facilities used in this work.

\section{References}

[1] S. L. Tisdale, W. L. Nelson, J. D. Beaton, and J. L. Havlin, Soil Fertility and Fertilizer, Prentice Hall, Upper Saddle River, NJ, USA, 5th edition, 1993.

[2] I. A. Jaiyeoba, "An assessment of soil fertility restoration under fallow in Nigerian savannah," Soil Use and Management, vol. 13, no. 3, pp. 163-164, 1997.

[3] C. D. Foy, R. L. Chaney, and M. C. White, "The physiology of metal toxicity in plants," Annual Review of Plant Physiology, vol. 29, pp. 511-566, 1978.

[4] V. O. Ajibola and R. Rolawanu, "Trace elements in the environment," Journal of Scientific and Industrial Research, vol. 59, no. 2, pp. 132-136, 2000.

[5] A. Aubert and M. Pinta, "Trace elements in soils", in Development in Soil Science, vol. 7, pp. 43-95, Elsevier, Amsterdam, The Netherlands, 1977.
[6] I. O. B. Ewa and L. A. Dim, "Major, minor and trace element determinations from a Nigerian aquatic sediment," Journal of Environmental Science and Health, vol. 24, no. 3, pp. 243-254, 1989.

[7] S. C. Hodges, Soil Fertility Basics, Soil. Science Extension North Carolina State University Certified Crop Advisor Training, 1995.

[8] P. A. Sanchez and T. J. Logan, "Myths and scienceabout the chemistry and fertility of soils in the Tropics," in Myths and Science of Soils of the Tropics, R. Lal and P. A. Sanchez, Eds., pp. 3546, Soil Science Society of America, Madison, Wis, USA, 1992.

[9] J. L. Ahlrichs, "The soil environment," in Organic Chemicals in the Soil Environment, C. A. I. Goring and J. W. Hamaker, Eds., Marcel Dekker, New York, NY, USA, 1972.

[10] J. O. Adejuwan, "A biogeographical survey of the dynamics of Savannah vegetation in Nigeria," Geographical Journal, vol. 14, pp. 31-48, 1971.

[11] I. O. B. Ewa, M. O. A. Oladipo, L. A. Dim, and S. P. Mallam, "Major, minor and trace elements of the Samaru savannah soil in Nigeria," Journal of Trace and Microprobe Techniques, vol. 18, no. 3, pp. 389-395, 2000.

[12] J. C. Menaut, R. Barbault, P. Lavelle, and M. Lepage, "African Savannas: biological systems ofhumification and mineralization," in Ecology and Management of the World's Savannas, J. C. Tothill and J. J. Mott, Eds., pp. 14-33, Australian Academic Science, Canberra, Australia, 1985.

[13] I. O. B. Ewa and L. A. Dim, "Major, minor and trace element determinations from a Nigerian aquatic sediment," Journal of Environmental Science and Health, vol. 24, no. 3, pp. 243-254, 1989.

[14] V. Y. Borkhodoev, "X-ray fluorescence determination of rubidium, strontium, yttrium, zirconium and niobium in rocks," Journal of Trace and Microprobe Techniques, vol. 16, no. 3, pp. 341352, 1998.

[15] O. G. Duliu, L. C. Dinescu, and D. Skliros, "INAA study of the distribution of some major and trace elements in Greek limestones and marbles," Journal of Trace and Microprobe Techniques, vol. 17, no. 2, pp. 165-175, 1999.

[16] A. R. Bromfield, "Sulphur in northern Nigerian soils: the effects of cultivation and fertilization on total socilsulpur and sulphate pattern in soil profile," Journal of Agriculture Science, vol. 78, pp. 465-470, 1972.

[17] M. E. Mosugu, V. O. Chude, I. E. Esu, T. Kparmwang, and W. B. Malgwi, "Contents and profile distribution of three forms of free iron oxides in three ultisols and an Alfisol in Nigeria," Communications in Soil Science and Plant Analysis, vol. 30, no. 7-8, pp. 1013-1024, 1999.

[18] K. K. Deshmukh, Central Region Neutron Activation Analysis at GSI Laboratory, Geological Survey of India, Pune, India, 2000.

[19] D. De Soete, R. Gijbels, and J. Hoste, Neutron Activation Analysis, John Wiley \& Sons, London, UK, 1972.

[20] Ehmann, W. D, and D. E. Vance, Radiochemistry and Nuclear Methods of Analysis, vol. 116 of Chemical Analysis: A Series of Monographs in Analytical Chemistry and Its Applications, John Wiley \& Sons, New York, NY, USA, 1990.

[21] J. Csikai, Handbook of Fast Neutron Generators, vol. 1-2, CRC Press, Boca Raton, Fla, USA, 1987.

[22] K. Heydorn, Neutron Activation Analysis For Clinical Trace Element Research, vol. 1-2, CRC Press, Boca Raton, Fla, USA, 1984.

[23] S. J. Parry, Activation Spectrometry in Chemical Analysis, vol. 119 of Chemical Analysis: A Series of Monographs in Analytical Chemistry and Its Applications, John Wiley \& Sons, New York, NY, USA, 1990. 
[24] J. Tolgyessy and E. H. Klehr, Nuclear Environmental Chemical Analysis, Series in Analytical Chemistry, Ellis Horwood, Chichester, UK, 1987.

[25] J. Tolgyessy and M. Kyrs, Radioanalytical Chemistry, vol. 1-2, Ellis Horwood, Cichester, UK, 1989.

[26] I. M. Klthoff and P. J. Elving, "Nuclear activation and radioisotope methods of analysis," in Treatise on Analytical Chemistry, John Wiley \& Sons, New York, NY, USA, 1986.

[27] E. Witkowska, K. Szczepaniak, and M. Biziuk, "Some applications of neutron activation analysis: a review," Journal of Radioanalytical and Nuclear Chemistry, vol. 265, no. 1, pp. 141-150, 2005.

[28] I. O. Abugassa, S. Sarmani, and U. El-Ghawi, "Instrumental neutron activation analysis based on $k_{0}$-standardization method as compared with other methods in the analysis of the IAEA inter-comparison test," Journal of Radioanalytical and Nuclear Chemistry, vol. 259, no. 3, pp. 381-384, 2004.

[29] J. H. Chao, Y. C. Sun, C. J. Chen, C. L. Tseng, and M. H. Yang, "Determination of trace $\mathrm{Al}$ in silicon carbide by epithermal neutron activation," Applied Radiation and Isotopes, vol. 62, no. 4, pp. 561-567, 2005.

[30] S. A. Jonah, I. M. Umar, M. O. A. Oladipo, G. I. Balogun, and D. J. Adeyemo, "Standardization of NIRR-1 irradiation and counting facilities for instrumental neutron activation analysis," Applied Radiation and Isotopes, vol. 64, no. 7, pp. 818-822, 2006.

[31] R. H. Filby, "Neutron Activation Analysis, Isotopic and nuclear analytical techniques in biological systems: a critical study, part IX," Pure and Applied Chemistry, vol. 67, no. 11, pp. 1929-1941, 1995.

[32] W. Liyu, WINSPAN (2004), A Multi-Purpose Gamma-Ray Spectrum Analysis Software, CIAE, Beijing, China, 2004.

[33] R. L. Njinga, S. A. Jonah, I. O. B. Ewa, M. O. A. Oladipo, and G. A. Agbo, "Alternative approach for efficiency data generation in neutron activation analysis," International Journal of Applied Science and Technology, vol. 1, no. 5, pp. 244-256, 2011.

[34] E. E. Schulte, Soil and Applied Iron, Understanding Plants Nutrients A3554, 2000.

[35] M. O. A. Oladipo, R. L. Njinga, A. Baba, and H. L. Muhammad, "Evaluation of trace elements in some northern-Nigeria traditional medicinal plants using INAA technique," Applied Radiation and Isotopes, vol. 70, no. 6, pp. 917-921, 2012.

[36] E. Epstein, Mineral Nutrition of Plants: Principles and Perspectives, John Wiley \& Sons, New York, NY, USA, 1972.

[37] H. D. Chapman, Ed., Diagnostic Criteria For Plants and Soils, University of California, Riverside, Calif, USA, 1972.

[38] I. Pais, M. Fehér, E. Farkas, Z. Szabó, and I. Cornides, “Titanium as a new trace element," Communications in Soil Science and Plant Analysis, vol. 8, pp. 407-410, 1977.

[39] A. M. Ure and J. R. Bacon, "Comprehensive analysis of soils and rocks by spark-source mass spectrometry," The Analyst, vol. 103, no. 1229 , pp. 807-822, 1978 .

[40] V. Romheld and H. Marscher, "Function of micronutrients in plants," in Micronutrients in Agriculture, J. Mortredt, F. R. Cox, L. M. Shuman, and R. M. Welch, Eds., Soil Science Society of America, Madison, Wis, USA, 1991. 


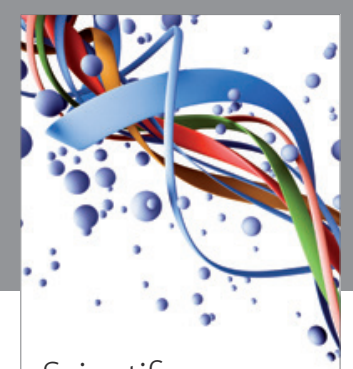

Scientifica
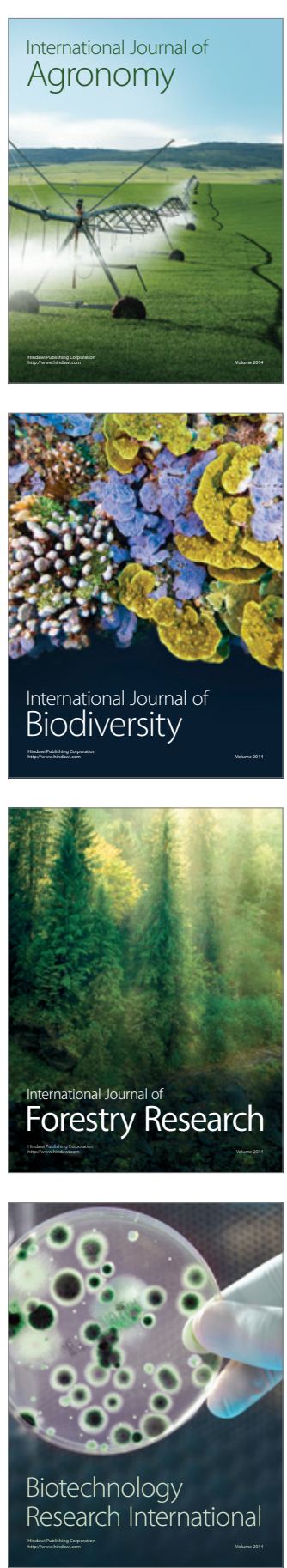


The Scientific World Journal
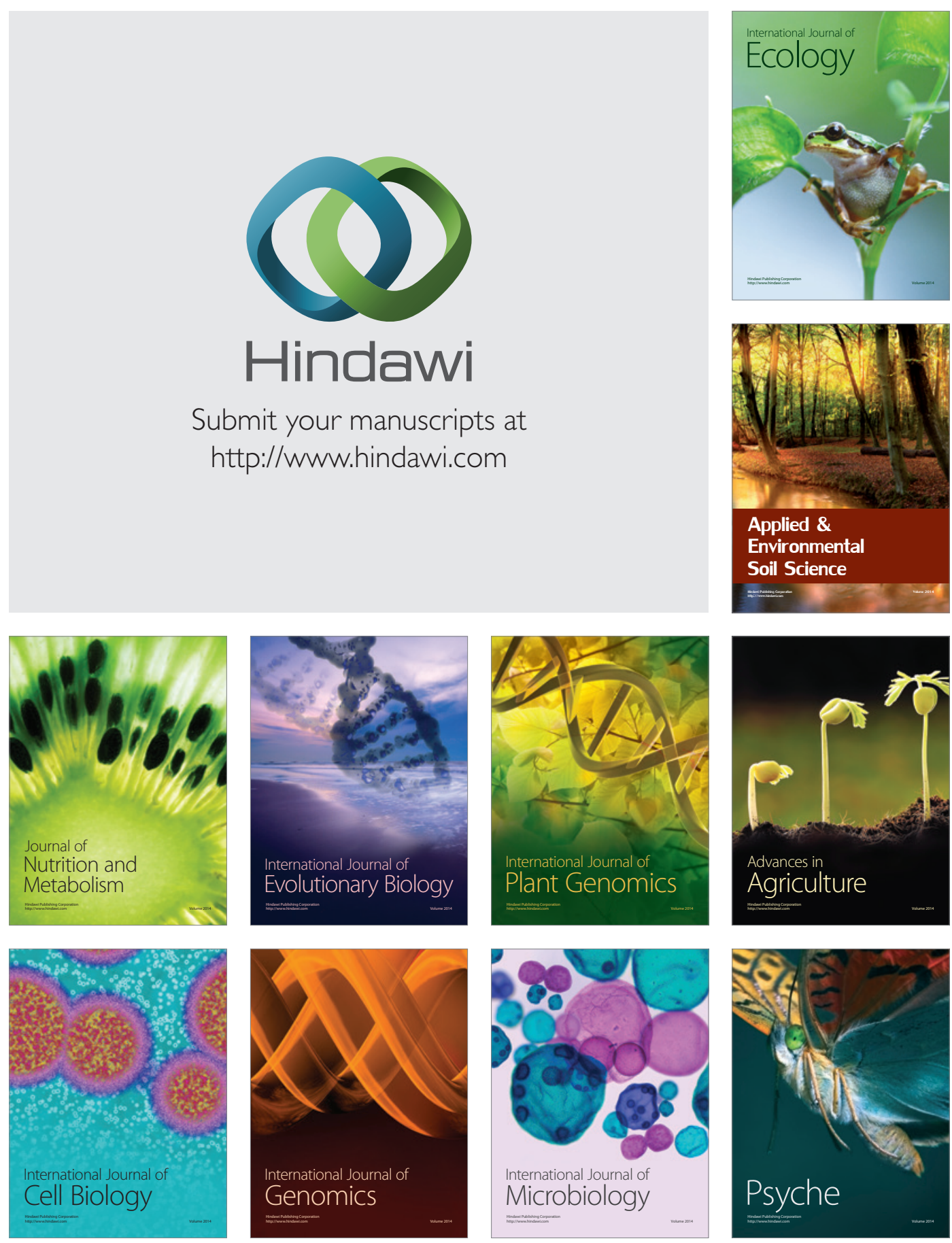